\title{
Endophyte-mediated multitrophic interactions in Lolium pratense
}

\author{
P. LEHTONEN ${ }^{1}$, M. HELANDER ${ }^{1}$ and K. SAIKKONEN ${ }^{2}$ \\ ${ }^{1}$ MTT Agrifood Research Finland, Plant Production Research, Plant Protection, FIN-31600 Jokioinen, Finland \\ ${ }^{2}$ MTT Agrifood Research Finland, Environmental Research, Karilantie 2 A, 50600 Mikkeli, Finland
}

paivi.lehtonen@mtt.fi

\begin{abstract}
The nature of plant-endophyte relationships may be affected by the addition of interacting species. Firstly, we show how the root hemiparasitic plant (Rhinanthus serotinus) can steal defending mycotoxins produced by the symbiotic endophytic fungus (Neotyphodium uncinatum) living within their shared host grass (Lolium pratense). The uptake of defensive mycotoxins from the endophyte infected host increases resistance of the hemiparasitic plant to the aphid (Aulacorthum solani). Endophyte infection increased performance of the hemiparasite but reduced the growth of the host grass, changing the mutualistic endophytic fungus to parasitic. Secondly, we present the interactions among endophyte, host plant, aphid herbivore (Rhopalosiphum padi) and aphid transmitted grass virus (BYDV). Endophyte infection lowered the frequency of BYDV in $L$. pratense. The reproduction of $R$. padi aphids was decreased on endophyte-infected plants compared to uninfected. With these results we would like to emphasise the importance of experiments with several community members to shed light on the complexity of endophyte-mediated community interactions.
\end{abstract}

Keywords: Lolium pratense, Neotyphodium uncinatum, Rhinanthus serotinus, BYDV, aphid, multitrophic interactions

\section{Introduction}

Experimental research on systemic fungal endophytes has mostly focused on direct, pairwise interactions between host plant and fungal endophytic symbiont, or tripartite interactions, including herbivores (e.g. Clay 1988; Bacon 1993; Breen 1994; Saikkonen et al. 1998). Species interactions in natural systems, however,
120

$\begin{array}{ll}100 \\ \\ 80 \\ & 60 \\ & 40 \\ & \\ & \\ & 0 \\ & \end{array}$

$* *$

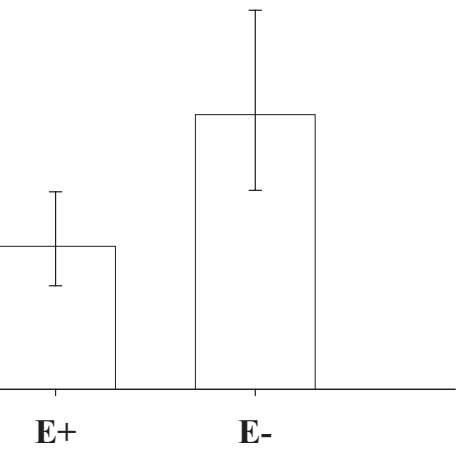

Endophyte status
Figure 1 Number of aphids (Aulacorthum solani) on a hemiparasite (Rhinanthus serotinus) of grass host (Lolium pratense) with $(\mathrm{E}+)$ and without (E-) infection by Neotyphodium uncinatum. Data are back-transformed estimates of least-squares means and 95\% confidence limits. ${ }^{* *} \mathrm{P}<0.01$. (Lehtonen et al. 2005a). are likely to be more complex. The nature of the plant-fungus relationship varies from antagonistic to mutualistic, depending, for example, on other community interactors and environmental conditions (Saikkonen et al. 2004; Müller \& Krauss 2005; Lehtonen 2006).

Studies examining endophyte-mediated interactions have concentrated on two widely used pasture and turf grasses, Lolium arundinaceum and Lolium perenne. In the Nordic countries, Lolium pratense is commonly used as a ley and pasture grass; it also often occurs outside agronomic use in meadows and on roadsides (Hämet-Ahti et al. 1998) and is commonly infected by an endophyte (Saikkonen et al. 2000). Endophyte-mediated interactions in $L$. pratense are poorly known. Knowledge gained from studies examining these interactions could be valuable from both agronomic and ecological perspectives.

We present here two experiments performed on Lolium pratense infected by Neotyphodium uncinatum. Firstly, we studied endophyte-mediated effects on the interactions among $L$. pratense, its hemiparasitic plant (greater yellow rattle Rhinanthus serotinus) and the herbivore of the hemiparasite (foxglove aphid Aulacorthum solani) (Lehtonen et al. 2005a). Secondly, we examined the effects of endophyte infection on aphid transmitted barley yellow dwarf virus (BYVD) infection frequencies (Lehtonen et al. 2006).

\section{Methods}

Hemiparasite experiment

In the hemiparasite experiment, seeds of hemiparasitic $R$. serotinus were collected from southwestern Finland during summers 2002-

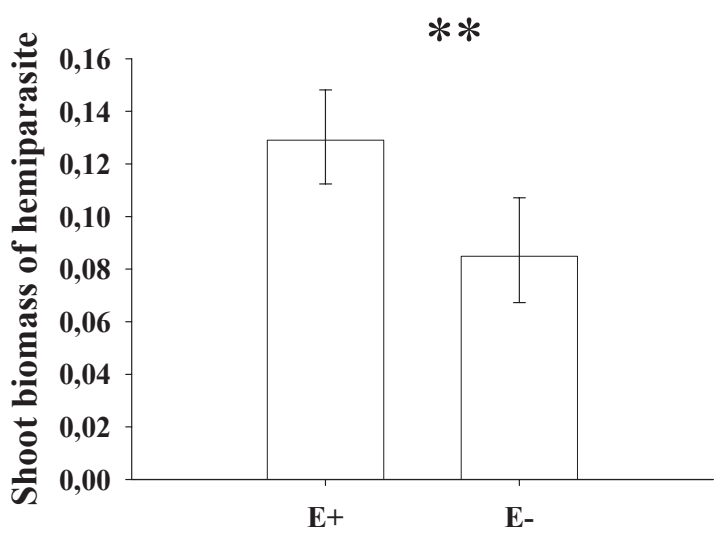

Endophyte status

Figure 2 Biomass of a hemiparasitic plant (Rhinanthus serotinus) parasitising endophyte-infected $(E+)$ and endophyte-free (E-) host grass. Data are back-transformed estimates of least squares means and $95 \%$ confidence limits. ${ }^{* *} \mathrm{P}<0.01$. (Lehtonen et al. 2005a). 


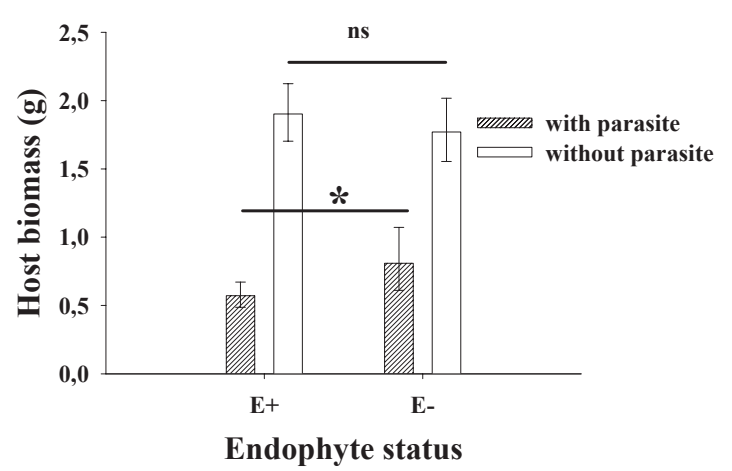

Figure 3 Biomass of $L$. pratense with $(E+)$ and without ( $E-$ ) infection by $N$. uncinatum and parasitism by $R$. serotinus. Data are back-transformed estimates of least squares means and 95\% confidence limits.* $\mathrm{P}<0.05$; ns - not significant (Lehtonen et al. 2005a).

2003. The infection status of the experimental L. pratense plants (commercial cultivar Kasper and pasture-collected unknown ecotype) was confirmed by staining and microscope examination of leaf samples. Two pots with hemiparasitic plants, one with endophyte infected (E+) and one with endophyte-free (E-) host grass, were placed within a plastic cylinder sealed with organza $(E+: n=41, E-: n=32)$. Then, four aphids were introduced into the cylinders and allowed to reproduce on their preferred host for 17 days. The experiment was set up as randomised design with controls without aphids on hemiparasites and controls without the parasitic plants (without aphids $E+: n=21, E-: n=6$; without parasitic plants $\mathrm{E}+: \mathrm{n}=60, \mathrm{E}-\mathrm{n}=43$ ). At harvest, aphids were counted, roots cleaned and haustorial connections between the hemiparasite and host grass were affirmed, number of grass tillers and hemiparasite flowers were counted, and finally, plant parts were dried $\left(2 \mathrm{~d},+50{ }^{\circ} \mathrm{C}\right)$ and weighed. To determine whether alkaloids of endophyte origin are transferred from the shared host grass to the hemiparasitic plant, we analysed the alkaloid content from 11 samples (plant individuals) of uninfected L. pratense, 6 samples of $R$. serotinus grown with uninfected L. pratense, 30 samples of endophyte-infected $L$. pratense and 25 samples of $R$. serotinus grown with endophyte-infected $L$. pratense. Alkaloid extraction and analysis were carried out according to Woldemichael and Wink (2002).

\section{BYDV experiment}

In the virus experiment, we used mature L. pratense plants, randomly chosen from an old pasture located in southwestern Finland (Lehtonen et al. 2005b) and transplanted into a common garden near to the pasture in August 2001. Plants were randomly arranged in four blocks with seven endophyte-infected (E+) and seven uninfected (E-) plants in each block. Samples were taken from each plant and checked for the presence of BYDV before beginning the experiment. Twenty-five Rhopalosiphum padi aphids carrying BYDV were released into each block and were left to reproduce for 2 months. The blocks were covered with organdy cages $(1.5 \times 1.5 \times 1 \mathrm{~m}$ [height] $)$ to prevent viral infections from spreading to neighbouring vegetation. The soil was nutrient-rich and high in organic matter (manured the previous spring). The plants were harvested in October 2001,

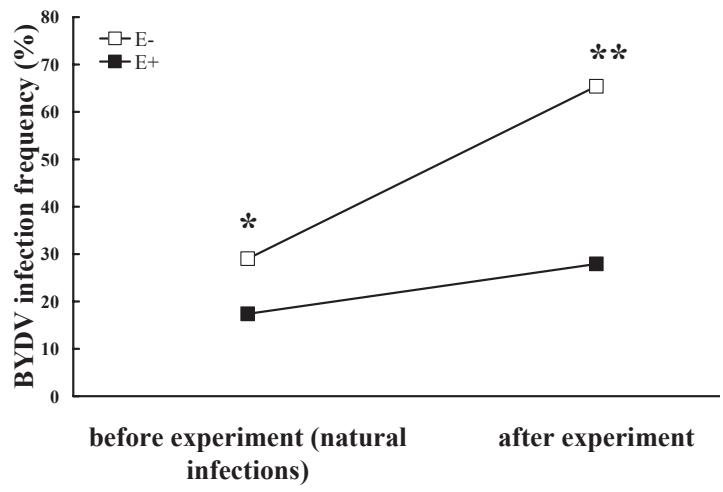

Figure 4 Effects of endophyte infection on BYDV infection frequency (\%) before the experiment (plants naturally BYDV-infected in the field before transplantation) and after the experiment in the common garden. E+: endophyte-infected plants, E-: endophyte-free plants. * $\mathrm{P}<0.05$; ${ }^{\star \star} \mathrm{P}<0.01$ (Lehtonen et al. 2006)

aphids were counted and samples for BYDV analysis were taken. Tillers were dried and weighed.

\section{Results}

Hemiparasite experiment

Endophyte-origin loline alkaloids were detected to be transferred from the endophyte-infected $L$. pratense host to the $R$. serotinus hemiparasite via root connections. The aphid $A$. solani was deterred by these alkaloids on $R$. serotinus (Fig. 1). Hemiparasites grown on $\mathrm{E}+$ hosts were bigger and produced more flowers than hemiparasites on E- hosts (Fig. 2). This could be partly due to reduced herbivory (although this was not statistically significant) or to changes in E+ host nutrient metabolism (Lyons et al. 1990; Malinowski \& Belesky 1999), which would benefit the growth of the hemiparasite. The growth of $\mathrm{E}+$ host plants was reduced in the presence of the hemiparasite as compared to parasitised E- plants (Fig. 3). There was no difference between E+ and E- $L$. pratense growth when these plants were not parasitised (Fig. 3).

\section{BYDV experiment}

Endophyte infection appeared to protect $L$. pratense against barley yellow dwarf virus. E + L. pratense plants harboured fewer viral infections than E- plants in both natural pasture and common garden conditions (Fig. 4). The reproduction of $R$. padi aphids decreased on endophyte-infected plants relative to uninfected plants. We assume that the poor performance of aphids on $\mathrm{E}+$ plants is the main reason for the lower BYDV infection frequency in $\mathrm{E}+L$. pratense, although a physiological cause is also possible.

\section{Discussion}

The consequences of the addition of other interacting species to purported mutualistic interactions are diverse and not easy to predict. Our results and other recent studies with other types of mutualists and antagonists (e.g. predators, herbivores and pathogens) suggest that the direction and magnitude of pairwise interactions may change with the addition of interacting species (Wootton 1993; Gange et al. 2002; Saikkonen et al. 2004; Strauss \& Irwin 2004). 
The nature of the symbiosis between the endophyte and $L$. pratense became clearly parasitic when the grass was parasitised by the hemiparasitic Rhinanthus serotinus (Lehtonen et al. 2005a). In this study, endophyte infection of the host plant increased the performance of the hemiparasitic plant, but reduced the growth of the host grass. In environments where these species co-occur, the costs of endophyte infection may thus outweigh the benefits. Similar results have been found in other recent studies using mycorrhizal fungi and hemiparasitic plants (Press \& Phoenix 2005). This was the first study to examine effects of hemiparasitism in E+ grasses, and the first time that endophyte-originated alkaloid transfer to another plant has been demonstrated. Because endophyte-originated alkaloids have been shown to deter a wide variety of vertebrate and invertebrate herbivores (Siegel \& Bush 1997), transferred alkaloids from the host grass may affect many types of herbivores feeding on the hemiparasites including the aphids that were deterred in this study. A similar phenomenon of alkaloid transfer followed by increased resistance has been reported, not only in other hemiparasitic plants (Adler 2000; Adler et al. 2001), but also in several adapted insects which circumvent plant defenses and take advantage of the alkaloids for their own anti-predator defense (e.g. Nishida 2002). Our results for the host-endophytehemiparasite-herbivore interactions provide further evidence on how the outcomes of endophyte-mediated interactions are community dependent.

After the incorporation of a plant virus into the plantendophyte-herbivore system, another benefit of endophyte infection was detected besides decreased reproduction of aphids. E+ plants were infected by the aphid-transmitted plant virus (BYDV) less frequently than E- L. pratense plants (Lehtonen et al. 2006). Although potential disadvantages of viral infection on plant performance were not addressed, it is possible that BYDVfree plants show higher fitness (Catherall \& Parry 1987; Clarke \& Eagling 1994; Hesse \& Latch 1999). The results of these $N$. uncinatum -mediated interactions in L. pratense may have practical applications. The use of $\mathrm{E}+L$. pratense cultivars could be beneficial because aphid populations are likely to decrease in mature $\mathrm{E}+L$. pratense stands because of high resistance resulting from the presence of endophyte-originated alkaloids in the plants (Lehtonen 2006). Furthermore, E+ plants harbour fewer BYD virus infections, and even if BYDV infects grasses without causing any direct loss of their fitness, its presence in the grass may serve as a reservoir for subsequent infection of other agricultural crops. Thus, a low infection rate of BYDV in $\mathrm{E}+$ L. pratense may protect adjacent grasses (including more susceptible cereals) from BYDV infections. The use of $\mathrm{E}+L$. pratense as a biocontrol agent is a promising future application in Nordic agriculture.

\section{ACKNOWLEDGEMENTS}

We thank Michael Wink and Frank Sporer for help in alkaloid analyses, Kirsi Lehto and Shahid Siddiqui for help in BYDV analyses and Kalle Lehtonen for help in the field in BYDV experiment. These studies were financially supported by Academy of Finland, Finnish Cultural Foundation and Turku University Foundation.

\section{REFERENCES}

Adler, L.S. 2000. Alkaloid uptake increases fitness in a hemiparasitic plant via reduced herbivory and increased pollination. American Naturalist 156: 92-99.
Adler, L.S.; Karban, R.; Sharon, S.Y. 2001. Direct and indirect effects of alkaloids on plant fitness via herbivory and pollination. Ecology 82: 2032-2044.

Bacon, C.W. 1993. Abiotic stress tolerances (moisture, nutrients) and photosynthesis in endophyte-infected tall fescue. Agriculture, Ecosystems and Environment 44: 123-141.

Breen, J.P. 1994. Acremonium endophyte interactions with enhanced plant-resistance to insects. Annual Review of Entomology 39: 401-423.

Catherall, P.L.; Parry, A.L. 1987. Effects of barley yellow dwarf virus on some varieties of Italian, hybrid and perennial ryegrasses and their implication for grass breeders. Plant Pathology 36: 148-153.

Clarke, R.G.; Eagling, D.R. 1994. Effects of pathogens on perennial pasture grasses. New Zealand Journal of Agricultural Research 37: 319-327.

Clay, K. 1988. Fungal endophytes of grasses - a defensive mutualism between plants and fungi. Ecology 69: 10-16.

Gange, A.C.; Bower, E.; Brown, V.K. 2002. Differential effects of insect herbivory on arbuscular mycorrhizal colonization. Oecologia 131: 103-112.

Hämet-Ahti, L.; Suominen, J.; Ulvinen, T.; Uotila, P. 1998. Retkeilykasvio (Field Flora of Finland); Ed. 4. Finnish Museum of Natural History, Botanical Museum. Helsinki. 656 pp.

Hesse, U.; Latch, G.C.M. 1999. Influence of Neotyphodium lolii and barley yellow dwarf virus, individually and combined, on the growth of Lolium perenne. Australasian Plant Pathology 28: 240-247.

Lehtonen, P. 2006. Fungal endophyte mediated trophic interactions in grasses: from ecology to applications. $\mathrm{PhD}$ thesis. University of Turku.

Lehtonen, P.; Helander, M.; Wink, M.; Sporer, F.; Saikkonen, K. 2005a. Transfer of endophyte-origin defensive alkaloids from a grass to a hemiparasitic plant. Ecology Letters 8: 1256-1263.

Lehtonen, P.; Helander, M.; Saikkonen, K. 2005b. Are endophytemediated effects on herbivores conditional on soil nutrients? Oecologia 142: 38-45

Lehtonen, P.; Helander, M.; Lehto, K.; Siddiqui, S.; Saikkonen, K. 2006. Endophytic fungus decreases plant virus infections in meadow ryegrass. Biology Letters 2: 620-623.

Lyons, P.C.; Evans, J.J.; Bacon, C.W. 1990. Effects of the fungal endophyte Acremonium-coenophialum on nitrogen accumulation and metabolism in tall fescue. Plant Physiology 92: 726-732.

Malinowski, D.P.; Belesky, D.P. 1999. Neotyphodium coenophialum-endophyte infection affects the ability of tall fescue to use sparingly available phosphorus. Journal of Plant Nutrition 22: 835-853.

Müller, C.B.; Krauss, J. 2005. Symbiosis between grasses and asexual fungal endophytes. Current Opinion in Plant Biology 8: 450-456.

Nishida, R. 2002. Sequestration of defensive substances from plants by Lepidoptera. Annual Review of Entomology 47: 57-92.

Press, M.C.; Phoenix, G.K. 2005. Impacts of parasitic plants on natural communities. New Phytologist 166: 737-751.

Saikkonen, K.; Faeth, S.H.; Helander, M; Sullivan, T.J. 1998. Fungal endophytes: A continuum of interactions with host plants. Annual Review of Ecology and Systematics 29: 319-343.

Saikkonen, K.; Ahlholm, J.; Helander, M.; Lehtimaki, S.; Niemelainen, O. 2000. Endophytic fungi in wild and cultivated grasses in Finland. Ecography 23: 360-366.

Saikkonen, K.; Wali, P.; Helander, M.; Faeth, S. H. 2004. Evolution of endophyte-plant symbioses. Trends in Plant 
Science 9: 275-280.

Siegel, M.R.; Bush, L.P. 1997. Toxin production in grass/ endophyte associations. pp. 185-207. In: The Mycota. V. Part A, Plant Relationships. Eds. Carroll, G.C.; Tudzynski, P. Springer-Verlag, Berlin Heidelberg.

Strauss, S.Y.; Irwin, E. 2004. Ecological and evolutionary consequencies of multispecies plant-animal interactions. Annual Review of Ecology, Evolution and Systematics 35:
435-466.

Woldemichael, G.M.; Wink, M. 2002. Concomitant occurrence of pyrrolizidine and quinolizidine alkaloids in the hemiparasite Osyris alba L. (Santalaceae). Biochemical Systematics and Ecology 30: 139-149.

Wootton, J.T. 1993. Size-dependent competition - effects on the dynamics vs the end-point of mussel bed succession. Ecology 74: 195-206. 